\title{
Neurologist practice patterns in treatment of muscle cramps in Canada
}

\author{
Mary Jane Lim Fat ${ }^{2}$, Seint Kokokyi ${ }^{1}$ and Hans Dieter Katzberg ${ }^{1,2^{*}}$
}

\begin{abstract}
Recently an article provided patient perspectives on therapies and perceived effectiveness in preventing muscle cramps. However, there are few studies evaluating physicians' point of view in the management of this common symptom. In our study, we studied physician practice patterns in the treatment of muscle cramps by surveying a group of neurologists in Canada. We demonstrated that most physicians use a combination of pharmacological and non-pharmacological methods in treating muscle cramps. The most commonly used medications are baclofen, quinine and gabapentin, of which baclofen and quinine were reported to be the most tolerated.
\end{abstract}

Keywords: Muscle cramps, Baclofen, Quinine, Practice parameters

We read with great interest the article written by Blyton et al. evaluating patient experience of treatments for muscle cramps [1]. In 2010, we presented a review of existing literature on the treatment of muscle cramps [2], however, there have been few publications that bridge the gap between evidence-based medicine and clinical practice as this article does. In this commentary, we present additional data on the practice patterns of a group of Canadian neurologists in the management of muscle cramps in an effort to further connect this gap.

With the approval of University Health Network Research Ethics Board, two hundred and eighty four physicians were sent an invitation with informed consent to complete the survey. A total of 62 physicians responded of which 8 declined to participate. Physician experience ranged from those starting practice to over 30 years experience. Half of the physicians identified themselves as general neurologists and $25 \%$ as neuromuscular specialists. Four physicians among the fifty-four responders (7.4\%) prescribed no treatments for muscle cramps, while 38 physicians $(70.4 \%)$ used a combination of both pharmacological and non-pharmacological treatments. An equal number of physicians $(n=6,11.1 \%)$ prescribed only pharmacological or only non-pharmacological treatments. Forty-three percent of neurologists used multiple

\footnotetext{
* Correspondence: hans.katzberg@utoronto.ca

'Toronto General Hospital / University Health Network, 200 Elizabeth Street, Toronto, ON M5G 2C4, Canada

${ }^{2}$ University of Toronto, Faculty of Medicine, 1 King's College Circle, Toronto, ON M5S 1A8, Canada
}

\section{Biomed Central}

(c) 2013 Lim Fat et al.; licensee BioMed Central Ltd. This is an Open Access article distributed under the terms of the Creative Commons Attribution License (http://creativecommons.org/licenses/by/2.0), which permits unrestricted use, distribution, and reproduction in any medium, provided the original work is properly cited.

pharmacological treatments and $70.4 \%$ used multiple nonpharmacological agents. Table 1 shows the pharmacological and non-pharmacological agents used by neurologists in the treatment of muscle cramps. The most common nonpharmacological methods included hydration and stretching and the top 3 pharmacological agents were baclofen, quinine sulphate and gabapentin. Baclofen and quinine derivatives were identified equally as the best-tolerated medications.

Prescription-grade quinine appears to be one of the most effective medications for cramps according to neurologists in our study and "quite effective-100\% effective" in 14/18 patients in the Blyton study. Cramp away or crampeze in contrast, which contain much lower amounts of quinine than the $300 \mathrm{mg}$ of quinine used in most trials, is found to be useless or of little help most of the time. This type of data is important to patients and physicians, as prescription guidelines for quinine are country specific. The FDA (USA) and TGA (Australia) have banned the marketing of quinine derivatives for muscle cramps [3,4]. Although the intention of our questionnaire was not to identify adverse events associated with quinine, it does show that prescriptionstrength quinine continues to be prescribed frequently and with good tolerability in Canada. Other published reviews have supported the use of quinine derivatives for short-term administration (under 60 days) [5] and in the physician-supervised treatment of disabling cramps [2]. 
Table 1 Non-pharmacological and pharmacological agents used by neurologists $(n=54)$ in the treatment of muscle cramps, as well as the percentage of physicians who used each particular agent

\begin{tabular}{lcc}
\hline Factor & $\begin{array}{c}\text { Number of } \\
\text { physicians } \\
\text { prescribed, } \\
\mathbf{n}(\%)^{*}\end{array}$ & $\begin{array}{c}\text { Number of physicians } \\
\text { rating agent as } \\
\text { most tolerable, } \\
\mathbf{n}(\%)^{*}\end{array}$ \\
\hline $\begin{array}{l}\text { Non-Pharmacological } \\
\text { Treatment } \\
\text { Hydration }\end{array}$ & $36(66.7)$ & - \\
Stretching & $24(44.4)$ & - \\
Massage Therapy & $21(38.9)$ & - \\
Herbal remedies & $4(7.7)$ & - \\
Pharmacological Treatment & $29(53.7)$ & $11(20.4)$ \\
Baclofen & $27(50.0)$ & $5(9.3)$ \\
Quinine and its derivatives & $27(50.0)$ & $0(0.0)$ \\
Gabapentin & $15(27.7)$ & $0(0.0)$ \\
Carbamazepine & $12(22.2)$ & $13(16.7)$ \\
Verapamil & $9(16.7)$ & $0(0.0)$ \\
Vitamin B & $9(16.7)$ & $1(1.9)$ \\
Phenytoin & $5(9.2)$ & $0(0.0)$ \\
Diltiazem & $4(7.4)$ & $6(11.1)$ \\
Levetiracetam & $3(5.5)$ & $0(0.0)$ \\
Vitamin E & $1(1.9)$ & \\
Oxycarbazepine & 100 d & - \\
\hline
\end{tabular}

* Percent numbers do not add up to 100 due to multiple responses.

Both studies reported the frequent use of nonpharmacological agents in the management of muscle cramps, most commonly stretching and hydration. Although these interventions had limited perceived efficacy according to patients, the low risk makes them good options as first-line recommendations. A comprehensive list of over-the-counter and homeopathic treatments was presented in the Bylton paper. Although magnesium is used frequently by patients, we agree that it has a limited role in treating muscle cramps outside the setting of pregnancy. None of the physicians in our survey used magnesium and our review found no evidence for their use in idiopathic muscle cramps [2]. Information gathered in our survey also supplements the Blyton article, which presented limited data on prescriptions medications. Medications other than quinine included baclofen (used most frequently and with best tolerability), gabapentin, calcium channel blockers, clonazepam, diazepam, and mexilitine. Of all these medications, only calcium channel blockers have modest evidence for use in cramps [2].

There are methodology limitations in both questionnairebased studies, including recall bias, limited information on side effects and etiologies of cramps, including medications [6].
Although caution needs to be used in interpreting these results, we hope that they will provide information relevant to clinical practice as serve as a catalyst for additional case-control and treatment trials for muscle cramps.

Our study shows that a combination of pharmacological and non-pharmacological methods was employed in treating muscle cramps. Moreover, physicians turn to baclofen, quinine and its derivatives, and gabapentin for pharmacological agents.

Abbreviations
FDA: Food and Drug Administration; TGA: Therapeutics Good Association.

Competing interests

Dr. Lim Fat has no financial or non-financial competing interests.

Miss Kokokyi has no financial or non-financial competing interests.

Dr. Katzberg has no financial or non-financial competing interests.

\section{Authors' contributions}

MJLF participated in the design of the study, and faxed surveys to

neurologists. SK participated in the coordination of the study, mailed surveys to non-responders and reconciled all completed surveys. HDK participated in the design of the study, e-mailed surveys to non-responders and supervised the study. All authors performed statistical analysis, helped to draft the manuscript, read and approved the final manuscript.

Received: 27 November 2012 Accepted: 18 December 2012

Published: 9 January 2013

\section{References}

1. Blyton F, Chuter V, Burns J: Unknotting night-time muscle cramp: a survey of patient experience, help-seeking behaviour and perceived treatment effectiveness. J Foot Ankle Res 2012, 5:7.

2. Katzberg HD, Khan AH, So YT: Assessment: Symptomatic treatment for muscle cramps (an evidence-based review): Report of the therapeutics and technology assessment subcommittee of the American Academy of Neurology. Neurology 2010, 74(8):691-696.

3. Food and Drug Administration: Department of Health and Human Services. Drug products containing quinine; enforcement action dates. Fed Regist 2006, 71:75557-75560.

4. Quinine indications - cramps deleted. Aust Adv Drug React Bull 2004, 23.

5. El-Tawil S, Al Musa T, Valli H, Lunn MP, El-Tawil T, Weber M: Quinine for muscle cramps. Cochrane Database Syst Rev 2010, 8:12.

6. Garrison SR, Colin RD, Morrow RL, Carney GA, Khan KM: Nocturnal leg cramps and prescription use that precedes them: A sequence symmetry analysis. Arch of Int Med 2012, 172:120-126.

doi:10.1186/1757-1146-6-2

Cite this article as: Fat et al:: Neurologist practice patterns in treatment of muscle cramps in Canada. Journal of Foot and Ankle Research 2013 6:2

\section{Submit your next manuscript to BioMed Central and take full advantage of:}

- Convenient online submission

- Thorough peer review

- No space constraints or color figure charges

- Immediate publication on acceptance

- Inclusion in PubMed, CAS, Scopus and Google Scholar

- Research which is freely available for redistribution 